\title{
Impacto de la pandemia en la práctica de los profesionistas de la salud oral en México.
}

\author{
Impact of the COVID-19 pandemic in the oral \\ health professionals' practice in Mexico.
}

\author{
Karla Eugenia Miguelena-Muro,* María Isis García-Esquibel,* Lorena López-González,* Alfredo Garcilazo-Gómez,*,‡ \\ Gustavo Tenorio-Torres,* Francisco David Jiménez-Díaz*
}

\section{RESUMEN}

A partir de la pandemia, los odontólogos han presentado una serie de complicaciones en su práctica diaria, la naturaleza misma de la profesión representa un alto riesgo de contagio y la posibilidad de generar una infección cruzada por el virus SARS-CoV-2, por lo que han tenido que limitar su labor a la atención de urgencias, adquiriendo insumos relacionados a incrementar los cuidados de su grupo de trabajo y del paciente. Objetivo: Conocer el impacto de esta plaga en la práctica de los profesionistas de la salud oral en México. Material y métodos: Se realizó un estudio descriptivo y transversal mediante la aplicación de una encuesta a través de redes sociales a odontólogos, los resultados se expresaron con tablas de frecuencias y porcentajes. Resultados: Se recibieron respuestas de 200 cirujanos dentistas con clínica privada, $71 \%$ comentó haber cerrado su consultorio al inicio de esta calamidad, en contraste, el $53.5 \%$ de profesionales afirmaron tener actualmente una consulta no restringida, refiriendo que se ha visto reducida entre $50 \mathrm{y}$ $75 \%$, la mayoría reconoce que han tenido que reforzar el uso de EPP y algunos protocolos de protección, 16.5\% ha padecido COVID-19. Conclusiones: La pandemia ha generado un impacto económico importante en la práctica de los odontólogos, al combinarse la disminución del número de pacientes con el aumento de gastos. Se debe considerar a la odontología como una profesión de alto riesgo, por lo que este gremio debe ser tomado en cuenta para el plan de vacunación como parte importante del sector salud.

Palabras clave: SARS-CoV-2, consulta dental, COVID-19, odontólogos, pandemia.

\section{ABSTRACT}

Given the nature of their profession, the COVID-19 pandemic has brought complications in their daily practice to odontologists, who are at a high risk of contracting the disease, and the possibility of creating a cross infection by the SARS-CoV-2 virus. That is why odontologists have had to restrain their practice to attend to emergencies only and acquire consumables and equipment related to improve their patients'care and the safety of their work team. Objective: To know the COVID-19 pandemic impact in the oral health professionals'practice in Mexico. Material and methods: A transversal, descriptive study was conducted by using a survey through social networks to gather information from odontologists practicing in Mexico. Results were presented in frequency and percentage tables. Result: Responses of 200 dental surgeons in private practice were received. $71 \%$ said that they closed their office at the beginning of the pandemic. On the other hand, $53.5 \%$ of them currently have a non-restricted practice but it is reduced between 50 and $75 \%$. Most of them recognized that they had to improve the use of PPE and add some protection protocols, $16.5 \%$ have suffered from COVID-19. Conclusions: This pandemic has generated an important economic impact in the odontological practice, combining the decrease in the number of patients with the increase in their office expenses. Odontology must be considered a high-risk profession and an important part of the health sector, consequently, these professionals must be included in the vaccination plan on a priority basis.

Keywords: SARS-CoV-2, dental practice, COVID-19, dentists, pandemic.

\section{www medigraphic org.mx}

\footnotetext{
* División de Ciencias Biológicas y de la Salud. Departamento de Atención a la Salud, Estomatología. Universidad Autónoma Metropolitana, México.

‡ División de Estudios Profesionales. Facultad de Odontología. Universidad Nacional Autónoma de México, México.

Recibido: 07 de abril de 2021. Aceptado: 08 de abril de 2021.

Citar como: Miguelena-Muro KE, García-Esquibel MI, López-González L, Garcilazo-Gómez A, Tenorio-Torres G, Jiménez-Díaz FD. Impacto de la pandemia en la práctica de los profesionistas de la salud oral en México. Rev ADM. 2021; 78 (3): 142-148. https://dx.doi.org/10.35366/100071
} 


\section{INTRODUCCIÓN}

E 30 de diciembre del 2020, la Organización Mundial de la Salud (OMS) etiqueta como una «emergencia de salud pública de carácter internacional» a la enfermedad COVID-19 (Coronavirus disease 19) generada por el nuevo coronavirus SARS-CoV-2 (Severe Acute Respiratory Syndrome Coronavirus 2), dando así inicio a una emergencia sanitaria en todo el mundo. ${ }^{1}$ En México, el primer caso confirmado se reportó ante las autoridades de la Secretaría de Salud el 27 de febrero del 2020 y para el 31 de marzo del 2021 se señaló que había 2,238,887 de casos confirmados y 203,210 defunciones confirmadas, cifras que van en aumento diariamente. ${ }^{2}$

Según la Organización Panamericana de la Salud (OPS), nueve de cada 10 personas en todo el mundo está en riesgo de tener algún tipo de enfermedad bucodental, lo cual incluye desde caries hasta enfermedades de las encías pasando por el cáncer de boca. ${ }^{3}$ Sin embargo, hoy en día el cuidado de la salud bucal representa un riesgo elevado de contagio y la posibilidad de generar una infección cruzada por el virus SARS-CoV-2 debido a las características específicas de los procedimientos que se realizan durante la consulta dental y el modo de transmisión del virus. ${ }^{4}$

Se sabe que el SARS-CoV-2 ingresa al huésped a través de la cavidad oral, nasal y mucosa conjuntival, buscando ensamblar su glucoproteína de superficie con los receptores de la enzima convertidora de angiotensina 2 (ECA2), con expresión genética en las células escamosas de la mucosa de la lengua seguidas por la mucosa del piso de boca, base de la lengua y glándulas salivales; una vez conectados, ambos receptores se activarán por la proteasa TMPRSS2 para darle ingreso a ese virión a la célula huésped y formar nuevos viriones potencialmente infecciosos, convirtiendo a la cavidad oral no sólo en el lugar de inoculación sino también en un reservorio del virus. ${ }^{5}$

Si se considera que El SARS-CoV-2 se contagia de manera directa principalmente a través de gotas de saliva o secreción de la nariz producida por una persona infectada y aspirada por un huésped, el profesionista de la salud oral se puede convertir en blanco fácil, ya que mantiene atención directa y cercana por un tiempo prolongado con su paciente, ${ }^{4}$ además, el virus puede transportarse a través de aerosoles creados en ambientes odontológicos mediante el uso de piezas de mano de alta y baja velocidad, ultrasonidos, jeringas triples, succión, agua, por lo que la constante exposición a saliva, sangre y otros fluidos de personas infectadas representa un riesgo, ${ }^{4,6}$ el virus también podría contagiarse de manera indirecta, por contacto con superficies que se encuentren en el entorno inmediato y con objetos que se hayan utilizado en personas infectadas. ${ }^{7}$

Es sabido que la saliva juega un importante papel en la transmisión de la COVID-19, las investigaciones han demostrado, al menos, tres vías por las cuales el SARS-CoV-2 puede estar presente en la saliva del paciente infectado:

1. Presencia del virus en la parte superior e inferior del tracto respiratorio, con un continuo traspaso de secreciones de manera bidireccional.

2. En el torrente sanguíneo, mediante el líquido crevicular.

3. Por la colonización e infección de las glándulas salivales a través de la liberación de partículas en la saliva por medio de los conductos salivales. ${ }^{8}$

Se ha propuesto la hipótesis de que la bolsa periodontal puede ser un sitio o nicho anatómico que capaz de actuar como reservorio para el virus SARSCoV $-2,{ }^{9}$ inclusive se ha observado la existencia de una asociación entre la periodontitis con el gran riesgo de que las personas con COVID-19 puedan ingresar a la Unidad de Cuidados Intensivos (UCI), así como la necesidad de ventilación asistida y posibilidad de muerte, además de un incremento de biomarcadores inflamatorios que subrayan el agravamiento del cuadro de la enfermedad. ${ }^{10}$

La pandemia ha resultado tener un impacto negativo significativo en la salud y patrimonio de la sociedad $y$, sin lugar a dudas, la economía de los propios odontólogos de práctica pública y privada se ha visto afectada, debido a que no sólo han limitado la atención bucal a urgencias, viendo reducido su volumen de pacientes, sino también han tenido que adquirir equipo de protección personal (EPP), así como material, instrumentos e insumos relacionados a incrementar los cuidados del enfermo y de él mismo. ${ }^{11}$

El objetivo del presente estudio es conocer el impacto de la pandemia en la práctica de los profesionistas de la salud bucal en México.

\section{MATERIAL Y MÉTODOS}

Se realizó un estudio descriptivo y transversal que consistió en diseñar una encuesta en una de las herramientas disponibles en la web 2.0, en la aplicación Formularios de Google. Este programa permite, una vez delineado el cuestionario, su envío por redes sociales, incluyendo 


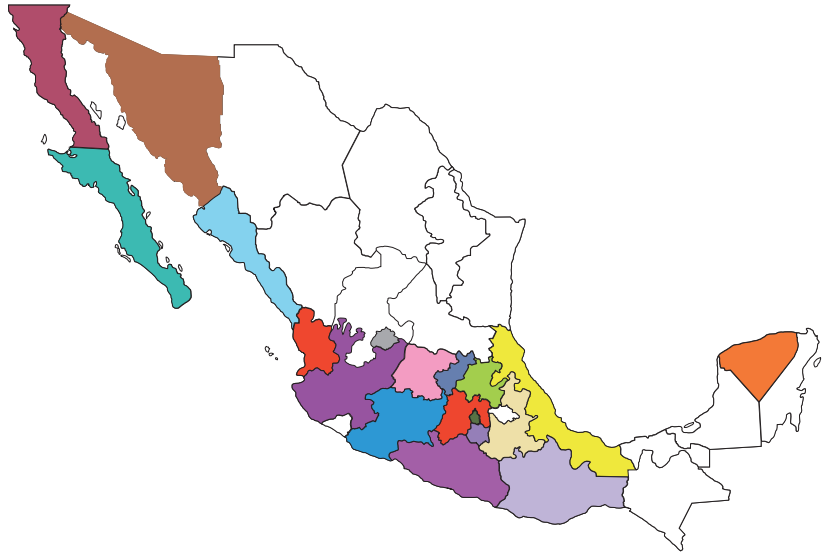

Figura 1: Estados de la República de donde se recibieron encuestas.

el enlace para contestarlo, siempre haciendo hincapié en que las respuestas tienen un carácter absolutamente anónimo, sin posibilidad de identificar a quien responde. La encuesta consistió en 27 preguntas de opción múltiple, dirigida a cirujanos dentistas de toda la República Mexicana, que tuvieran pacientes privados. El cuestionario se dividió en cinco rubros:

1. Datos generales y demográficos.

2. Labor profesional y características de la consulta privada antes y durante la pandemia.

3. Contagios por COVID-19.

4. Barreras y medidas de prevención al contagio del SARS-CoV-2 en el consultorio.

5. Infraestructura e instrumental adquirido buscando enfrentar a la COVID-19.

La solicitud de la participación se llevó a cabo entre el 19 de febrero y el 04 de marzo del 2021, los destinatarios se obtuvieron de contactos de los investigadores del proyecto, distribuyéndose por medio de las aplicaciones WhatsApp o Facebook. Los datos se exportaron a una hoja de Microsoft Excel analizándose por medio de estadística descriptiva, los resultados se expresaron con tablas de frecuencias y porcentajes.

\section{RESULTADOS}

Se recibieron un total de 200 encuestas contestadas, en donde $69.5 \%$ (139) fueron mujeres y el $30.5 \%(61)$ fueron hombres, el mayor grupo pertenece a quienes se encuentran entre 46 y 55 años (41\%), 44\% de los participantes cuenta con estudios de licenciatura, $46 \%$ son especialistas, $8 \%$ cuentan con maestría y $2 \%$ con doctorado. Se recibieron encuestas de 19 estados de la República Mexicana (Figura 1).

En cuanto a su labor profesional y características de sus pacientes, $65 \%$ respondieron que no trabajan en ninguna institución pública, $42 \%$ coinciden en que la consulta es su única fuente de ingresos y para $15.5 \%$ es un adicional a los mismos; $71 \%$ de los encuestados comenta que cerraron su consultorio al inicio de la pandemia, a diferencia de $6 \%$ que refirieron no haber suspendido su servicio en ningún momento, 139 (53.5\%) profesionales dieron una respuesta afirmativa a la pregunta de contar con consulta no restringida, es decir que no está suspendida y no se limitan a ver sólo urgencias (Figura 2). Antes de la plaga, 36.5\% dedicaba más de 25 horas a la semana a sus pacientes privados (Figura 3 ), pero durante la pandemia $42 \%$ refieren dedicarle menos de 10 horas a la semana a la labor en su clínica (Figura 4) y más de la mitad (55.5\%) de los participantes comentan que su volumen de personas atendidas se ha visto reducido entre 50 y $75 \%$.

En relación al SARS-CoV2, 51\% de los dentistas encuestados no se ha practicado ninguna prueba PCR de detección de COVID-19, el resto (49\%) se ha practicado cuando menos una prueba de PCR, 39 profesionistas (19.5\%) encuestados refieren haber padecido esta enfermedad, de los cuales $28 \%$ considera haberse contagiado en su consultorio (Figura 5). El 70\% de los participantes comentan que han tenido pacientes que les han comunicado haber resultado positivos a COVID-19, retomando su tratamiento 30 días después de dar positivo a este virus, $41.8 \% 60$ días después del resultado positivo de

Por el momento, su consulta privada:

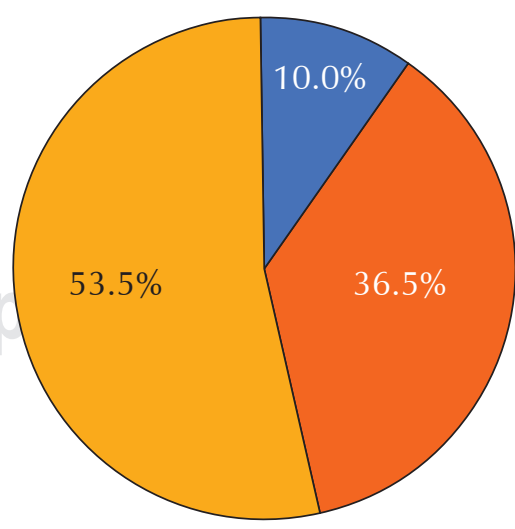

Está totalmente suspendida Limitada a urgencias Consulta activa

200 respuestas

Figura 2: Condición de la consulta actualmente. 
Antes de la pandemia, ¿̇uántas horas dedicaba a su consulta privada?

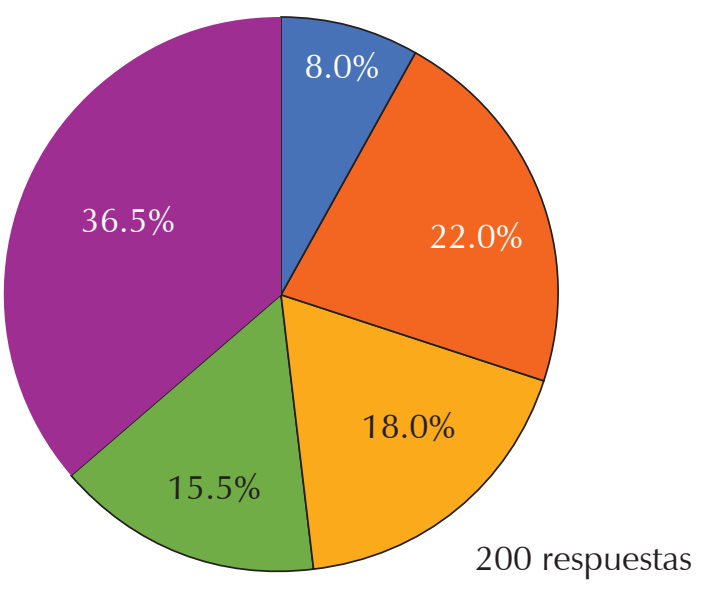

Menos de 10 horas a la semana

10 a 16 horas a la semana

16 a 22 horas a la semana

22 a 28 horas a la semana

Más de 28 horas a la semana

Figura 3: Horas dedicadas a la consulta privada, antes de la pandemia.

su prueba y $11.3 \%$ refieren que tales personas no han retomado su tratamiento odontológico.

En cuanto a las medidas de prevención al contagio del SARS-CoV-2 tomadas por los médicos que participaron en el estudio, más de $60 \%$ realiza triaje telefónico a sus pacientes y 108 de los encuestados comentan que, al ingreso a su clínica, a su paciente se le toma la temperatura, se le realiza oximetría y se le ofrece alcohol en gel. Un $43 \%$ trabajan solos en su consulta mientras que $28.5 \%$ sólo con asistente, 9\% con secretaria y un 19\% trabaja con asistente y secretaria; a la pregunta sobre si se ofrece algún enjuague bucal al paciente, previo a la atención estomatológica, 23\% respondieron que no, 31\% comentó que clorhexidina, el $17 \%$ peróxido de hidrógeno, 10.5\% yodo povidona y $10 \%$ cloruro de cetilpiridinio, el resto $(8.5 \%)$ manifestó ofrecer otro tipo de soluciones (bicarbonato de sodio, soluciones con cloro).

En cuanto al equipo de protección personal (EPP) la mayoría de los profesionistas refieren el uso de sobrebata, lentes, careta, respiradores KN95 o N95, gorro y guantes de látex o nitrilo, así como tener conocimiento de los protocolos de colocación y retiro del EPP. El 90.5\% comentan que higienizan el consultorio entre un paciente $y$ otro; $75.5 \%$ de los médicos participantes comentaron que cuentan con autoclave, 66 odontólogos comentan tener, además, tinas ultrasónicas, así como integrar a la clínica purificadores de aire con filtros HEPA, ozonificadores, aspiradores de aerosoles, humidificadores, ventiladores y vaporizadores de amonio entre otros aparatos. En cuanto a la inversión en instrumentos e infraestructura para poder atender a pacientes durante el tiempo de la pandemia, $37.5 \%$ considera que ha invertido entre $\$ 5,000$ y $\$ 10,000$ pesos mientras que $27 \%$ menos de $\$ 5,000$ pesos, $23 \%$ entre $\$ 10,000$ y $\$ 25,000$ pesos y $12.5 \%$ más de $\$ 25,000$ pesos.

Finalmente, de los 200 profesionistas que aceptaron participar sólo han sido vacunados siete, todos del sexo femenino, 96.5\% restante aún se encuentra en espera de ser vacunado.

\section{DISCUSIÓN}

El presente manuscrito muestra cómo la pandemia provocada por el SARS-CoV-2 ha generado un fuerte impacto en la consulta de los profesionales del área de la salud oral, provocado por el cierre de los consultorios en los

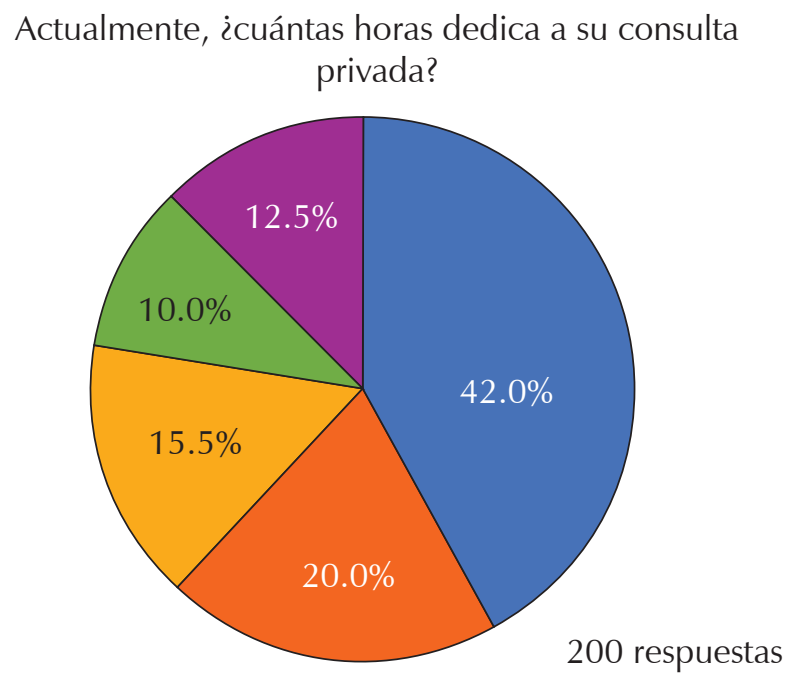

Menos de 10 horas a la semana

10 a 16 horas a la semana

16 a 22 horas a la semana

22 a 28 horas a la semana

Más de 28 horas a la semana

Figura 4: Horas dedicadas a la consulta privada, durante de la pandemia. 
¿Ha padecido COVID-19 (sintomático o asintomático)?

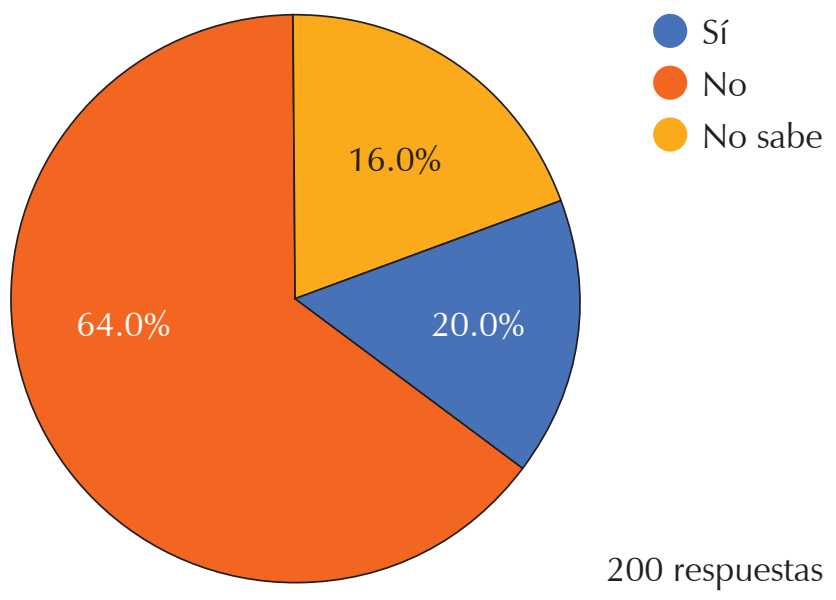

Figura 5: Profesionistas de la salud bucal que han padecido COVID-19.

primeros meses de la catástrofe, la ausencia de pacientes, la disminución de tiempo de atención, aunado a la preparación en infraestructura y equipo que protejan al odontólogo de algún contagio durante su desempeño, junto con medidas preventivas a fin de minimizar infecciones cruzadas. De acuerdo a Cavazos-López y cols., a principios de la pandemia, $61 \%$ de los odontólogos mexicanos estaban ofreciendo atención de urgencias, $33 \%$ no estaban realizando ningún procedimiento y $6 \%$ ofrecían su servicio con normalidad, ${ }^{12}$ datos similares a los obtenidos en el presente estudio, lo que contribuyó a la Jornada Nacional de Sana Distancia y para lo cual la CONAMED publicó una serie de infografías con recomendaciones tendientes a evitar el contagio por coronavirus en la clínica odontológica, recomendando limitar el servicio sólo a urgencias. ${ }^{13}$

Sin embargo, conforme la tragedia ha continuado, el incremento del servicio de la consulta normal ha sido evidente, como se puede apreciar en los resultados, en donde al inicio del 2021 ya $53.5 \%$ de profesionistas encuestados manifestaron tener una consulta no restringida. Con la meta de prestar atención estomatológica a pacientes, la Asociación Dental Americana (ADA) ha sugerido una serie de recomendaciones provisionales para la recuperación de la práctica odontológica durante la pandemia a medida que los consultorios vuelven a brindar cuidados que no son de emergencia, aunadas a las ya conocidas precauciones universales estándar procurando evitar el contagio cruzado en la práctica odontológica. ${ }^{14}$
Existen varios protocolos de atención en consultorio odontológico publicados, por lo que se debe tomar en cuenta:

1. Priorizar el bienestar del enfermo y de todo el grupo de trabajo.

2. Mantener la cantidad de personal en operación al mínimo requerido.

3. Realizar evaluación constante de la sintomatología de todo el personal.

4. Por vía telefónica, efectuar evaluación previa al paciente, con el fin de detectar probables casos de COVID-19.

5. Preingreso con cubrebocas (también para el personal del consultorio), ya que pueden existir partículas de aerosol que contienen virus.

6. Al ingreso a la clínica, medir la temperatura con termómetro a distancia y proporcionar alcohol en gel al $70 \%$.

7. Lavado de manos constante.

8. Desinfección de todas las superficies del mobiliario del consultorio.

9. ¿El sillón dental debe estar así? El mismo cubierto por un cubre sillones desechable o correctamente desinfectado.

10. A cada paciente debe preparársele una bandeja plástica desechable, con un vaso, un aspirador, una cánula desechable de la jeringa de aire o agua.

11. Previo al examen intraoral, se sugiere un enjuague bucal previo.

12. Uso adecuado del equipo de protección personal, siguiendo la correcta colocación.

13. Guantes desechables e impermeables de látex o nitrilo, mascarilla quirúrgica y protección ocular en procedimientos no generadores de aerosoles.

14. Guantes desechables e impermeables de látex o nitrilo, mascarillas N95 o equivalentes, protección ocular y delantal de manga larga impermeable y desechable, en procedimientos generadores de aerosoles.

15 Minimizar la producción de aerosoles siempre que se pueda.

16. En el caso de utilizar rotatorios de alta velocidad, acompañarlos de la doble aspiración del instrumental, o de algún sistema alternativo de aspiración forzada de aerosoles.

17. Se recomienda el uso del dique de hule en todos los casos que sea posible.

18. Trabajo a cuatro manos.

19. Ventilación del área de trabajo una vez que se ha retirado la persona.

20. Retiro de manera adecuada del EPP (equipo de protección personal). ${ }^{4,13-16}$ 
La mayoría de los odontólogos que respondieron el cuestionario han implementado las recomendaciones de bioseguridad emitidas por autoridades mexicanas e internacionales. Salvo en lo referente al enjuague ofrecido al paciente antes del procedimiento, pues se puede observar que, entre quienes respondieron, si ofrecían algún enjuague bucal la mayoría indicó a la clorhexidina como su preferida, siendo el peróxido de hidrógeno al $1 \%$, povidona yodada al $0.2 \%$ o cetilpiridinio las otras soluciones indicadas, ya que éstas pueden reducir la carga viral oral en sujetos infectados y disminuir el riesgo de transmisión en gotitas generadas en aerosoles, producidos durante los procedimientos odontológicos. ${ }^{15}$

Los odontólogos que participaron respondiendo el cuestionario, y que han tenido COVID-19, reportaron creer que habían sido infectados en su consultorio. La Secretaría de Salud de México, de acuerdo con los datos del Sistema de Vigilancia Epidemiológica de Enfermedad Respiratoria Viral (SISVER) reportó, hacia el 01 de marzo del 2021, que en cuanto a casos acumulados en personal médico infectado con SARS-CoV-2, $2 \%$ pertenecen a odontólogos $(4,563)$, y en defunciones confirmadas en personal de salud un 3\% (104) corresponden a este mismo grupo de profesionistas, precisando que la información no permite identificar el lugar del contagio. ${ }^{17}$

Como se puede advertir en los resultados del presente escrito, los odontólogos no sólo se enfrentan al riesgo de contraer la enfermedad, sino también están encarando problemas económicos al ver disminuido el número de personas y el tiempo dedicado a su consulta, aunado a la inversión en infraestructura que intenta hacer frente al virus en su consultorio, sin dejar de lado que para un número significativo su consulta representa la única fuente de ingresos. Benoit Varenne, responsable de Odontología en el Departamento de Enfermedades no Contagiosas de la OMS, comentó que: «La COVID-19 ha afectado los servicios dentales en una forma de la que no hay precedente, están reabriendo paulatinamente, pero las nuevas normalidades requieren una adaptación que necesitará tiempo e inversión». ${ }^{18}$ La Asociación Dental Irlandesa (IDA) reporta que alrededor de tres cuartas partes de los odontólogos esperan una pérdida financiera de más de $70 \%$ en medio del brote de este trastorno. ${ }^{19}$

Aun con las limitaciones del presente estudio, la relevancia del reporte radica en mostrar que los odontólogos han tenido que adoptar varias medidas para realizar su trabajo en una consulta limitada, así como enfrentarse a una serie de gastos no previstos, sin dejar de lado que representan un grupo en riesgo por la complejidad y cercanía con el paciente durante la atención odontológica.

\section{CONCLUSIONES}

Es importante remarcar que los odontólogos son parte del personal médico, quienes, además, por la naturaleza de su labor, se encuentran en constante exposición al virus SARS-CoV-2, principalmente en personas asintomáticas, condición por la cual debería ser considerada como una profesión de alto riesgo y ser tomados en cuenta dentro del plan de vacunación, esto permitirá una atención más segura para el profesional y el paciente. Ante la pandemia, la mayoría de los odontólogos inicialmente cerraron o limitaron su servicio a urgencias, viendo reducida su jornada laboral, reabrir los consultorios implicó que tuvieran que implementar una serie de protocolos e invertir en material e infraestructura, con el fin de brindarle al enfermo un cuidado adecuado, además de procurar seguridad para él y su equipo de trabajo, generando un impacto económico importante al combinarse la disminución de actividad con el aumento de gastos. Aun cuando la gran mayoría de los profesionistas de la salud oral que actualmente tiene una consulta no restringida ha adoptado medidas en sus clínicas, apegados a las recomendaciones de las autoridades, es de suma importancia que se mantengan en una continua actualización en materia de SARS-CoV-2 mediante canales de información serios y comprobados.

\section{REFERENCIAS}

1. Mahase E. China coronavirus: WHO declares international emergency as death toll exceeds 200. BMJ. [Internet] 2020 [Cited March 23, 2021]; 368: m408. Available in: https://www.bmj.com/ content/bmj/368/bmj.m408.full.pdf.

2. SSA/SPPS/DGE/DIE/InDRE/UIES/Informe técnico. COVID-19 / México. [Citado el 31 de marzo del 2021]. Disponible en: https:// www.gob.mx/cms/uploads/attachment/file/626482/Comunicado_ Tecnico Diario COVID-19 2021.03.31.pdf.

3. Mitchell C. PĀ HO/WHO [İnternet]. Paho.org. 2013 [Citado el 31 de marzo de 2021]. Disponible en: https://www.paho.org/hq/ index.php?option $=$ com_content $\&$ view $=$ article\&id $=8387: 2013$ oral-health-vital-overall-health\&ltemid=135\&lang=es).

4. Meng L, Hua F, Bian Z. Coronavirus disease 2019 (COVID-19): emerging and future challenges for dental and oral medicine. J Dent Res. 2020; 99 (5): 481-487.

5. Villanueva-Sánchez Francisco Germán, Escalante-Macías Lilia Haidé. SARS-CoV-2 Modelo de Inoculación en la Cavidad Oral. Revisión de la Literatura. Int J Odontostomat. 2020; [Citado 2021 Abr 02]; 14 (4): 495-500. Disponible en: https:// scielo.conicyt.cl/scielo.php?script $=$ sci arttext\&pid $=$ S0718381X2020000400495\&lng=es. http://dx.doi.org/10.4067/S0718$381 X 202000040049$.

6. Peng X, Xu X, Li Y, Cheng L, Zhou X, Ren B. Transmission routes of 2019-nCoV and controls in dental practice. Int J Oral Sci. 2020; 12 (1): 1-6.

7. Ong SW, Tan YK, Chia PY, Lee TH, Ng OT, Wong MS et al. Air, surface environmental, and personal protective equipment contamination 
by severe acute respiratory syndrome coronavirus 2 (SARS-CoV-2) from a symptomatic patient. JAMA. 2020.

8. Sabino-Silva R, Jardim ACG, Siqueira WL. Coronavirus COVID-19 impacts to dentistry and potential salivary diagnosis. Clin Oral Investig. 2020; 24 (4): 1619-1621.

9. Badran Z, Gaudin A, Struillou X, Amador G, Soueidan A. Periodontal pockets: A potential reservoir for SARS-CoV-2? Med Hypotheses. 2020; 143: 109907. doi: 10.1016/j.mehy.2020.109907.

10. Marouf N, Cai W, Said KN, Daas H, Diab H, Chinta VR et al. Association between periodontitis and severity of COVID-19 infection: a case-control study. J Clin Periodontol. 2021; 48 (4): 483-491. doi: 10.1111/jcpe.13435.

11. Cázares-de León F, Peraldi-Sada MG, Aneyba-López LD, SotoGámez DE. Impacto económico en el medio odontológico durante la pandemia del COVID-19: revisión integradora. Rev ADM. 2021; 78 (1): 42-47.

12. Cavazos-López E, Flores-Flores D, Rumayor-Piña Alicia, TorresReyes P, Rodríguez-Villarreal Óscar, Aldape-Barrios B. Conocimiento y preparación de los odontólogos mexicanos ante la pandemia por COVID-19. Rev ADM. 2020; 77 (3): 129-136.

13. Recomendación para prevenir el contagio por COVID-19 en el consultorio dental. CONAMED. [Internet] 2020. [Citado el 31 de marzo de 2021]. Disponible en: http://www.conamed.gob.mx/ gobmx/infografias/pdf/dental_covid19_c.pdf.

14. ADA. Return to Work Interim Guidance Toolkit.: American Dental Association; 2020 [cited March 25, 2021]. Available in: https:// success.ada.org/ /media/CPS/Files/Open\%20Files/ADA_Return_ to Work Toolkit.pdf.

15. Herrera $\bar{D}$, Serrano J, Roldán S, Sanz M. Is the oral cavity relevant in SARS-CoV-2 pandemic? Clin Oral Investig. 2020; 24 (8): 2925-2930.
16. Harrel SK, Molinari J. Aerosols and splatter in dentistry: a brief review of the literature and infection control implications. J Am Dent Assoc. 2004; 135 (4): 429-437.

17. Secretaría de Salud. Personal de Salud [Citado el 31 de marzo de 2021]. Disponible en: https://www.gob.mx/cms/ uploads/attachment/file/620537/COVID-19_Personal_de_ Salud_20210301.pdf.

18. Forbes Staff. Servicios dentales han sido olvidados por la pandemia, apunta la OMS. Forbes Magazine [Internet]. 11 de agosto de 2020 [Citado el 31 de marzo de 2021]; Disponible en: https://www.forbes. com.mx/noticias-servicios-dentales-olvidados-pandemia-oms.

19. Scale of dental collapse highlighted in survey [Internet]. Newsweaver.com. [Cited March 31, 2021]. Available in: https:// irishdentalassociation.newsweaver.com/newsletter/13ctcsav7cz1c ys22xtzj2 $\mathrm{a}=1 \& \mathrm{p}=56657247 \& \mathrm{t}=22322575$.

Conflicto de intereses: Los autores declaran no tener ningún conflicto de intereses.

Aspectos éticos: Previo llenado del cuestionario se les informó a los participantes sobre los objetivos del estudio, al mismo tiempo que se aseguró no ser posible conocer la identidad de quien contestara la encuesta. De la misma manera se adjuntó el consentimiento informado de los participantes.

Financiamiento: El estudio no ha recibido ningún tipo de aportación económica.

Correspondencia:

Alfredo Garcilazo Gómez

E-mail: agarcilazo@correo.xoc.uam.mx 